\title{
Exploratory Study on Taiwanese Secondary Teachers' Critiques of Mathematics Textbooks
}

\author{
Kai-Lin Yang ${ }^{1 *}$, Xin-Yi Liu ${ }^{1}$ \\ ${ }^{1}$ National Taiwan Normal University, TAIWAN \\ Received 8 April 2018 - Revised 19 September 2018 - Accepted 25 September 2018
}

\begin{abstract}
This study explores Taiwanese mathematics teachers' critiques of a series of geometry textbooks for grades 8 and 9. Two hundred seventy-four critiques from 143 mathematics teachers were analyzed by referring to six attributes of abstraction. Through analysis and interpretation of these critiques, the meaning of each attribute was refined, and their features were revealed. Possible beliefs-in-critiquing related to the features were discussed. This study contributes to the literature by advancing understanding of mathematics teachers' critiques of textbooks. We conclude with a discussion of the methodological and educational implications of teachers' critiques as well as how critiques of teaching materials can influence teacher education.
\end{abstract}

Keywords: geometry, mathematics teacher, teacher critique, textbook

\section{INTRODUCTION}

Explorations of the relationship between mathematics teachers and curriculum materials mainly focus on understanding how and why teachers use mathematics curriculum materials. This topic has become more popular and has made significant contributions to mathematics teaching (Lloyd, Remillard, \& Herbel-Eisenmann, 2009). These studies support the notion that effective use of curriculum materials requires that teachers take a critical stance towards these materials, and that professional vision can inform this critique (Drake, \& Sherin, 2009; Choppin, 2011).

\section{Curriculum-proof Teacher}

Considering variations in how teachers use curriculum materials, researchers have identified four ways of curriculum use (Remillard, 2005). On one end of the curriculum use spectrum is the idea of a teacher-proof curriculum', in which the curriculum is viewed as fixed and the teacher viewed as an enactor of the curriculum. On the other end is the concept of a 'curriculum-proof teacher', in which the relationship between the teacher and the curriculum is viewed as collaborative and participatory (Remillard, 2005; Taylor, 2013). Curriculum-proof teachers are able to assess the accessibility and appropriateness of curriculum materials for their students, and know how to adapt them if necessary (Taylor, 2013).

Many previous studies have applied the case-study method to conduct deep investigations of mathematics teachers' use of curriculum materials (Pepin, Gueudet, G., Trouche, 2013). For instance, teachers adapted curriculum materials by creating new components, replacing one component with something different, or omitting one component when evaluating some components as not being effective for students (Nicol \& Crespo, 2006; Sherin \& Drake, 2009). Moreover, other related studies investigated factors influencing how teachers interpreted curriculum materials and adapted teaching, e.g. mathematical knowledge, curriculum vision as well as inquiry in students' thinking (Charalambous, \& Hill, 2012; Choppin, 2011). These studies shared an interest in how or why mathematics teachers interact with curriculum materials.

(C) 2019 by the authors; licensee Modestum Ltd., UK. This article is an open access article distributed under the terms and conditions of the Creative Commons Attribution License (http://creativecommons.org/licenses/by/4.0/). 凹 kailin@ntnu.edu.tw (*Correspondence) $\bigotimes$ plantkiller@gmail.com 


\section{Contribution of this paper to the literature}

- This study contributes to literature on teachers' transformation of curriculum materials by advancing the understanding of mathematics teachers' critiques of textbooks.

- The attributes and features identified from mathematics teachers' critiques can serve as a frame for mathematics teachers to evaluate mathematics textbooks.

- Analyses of teachers' critiques of teaching materials shed light on their beliefs about the quality of mathematics textbooks.

Although these case studies provide unique insights into how and why teachers transform curriculum materials, researchers do not know well about which features of curriculum materials are considered by mathematics teachers to make a decision to adapt curriculum materials. Pragmatically, it is necessary for teachers to identify and critique features of curriculum materials before adapting them for students.

\section{Study Aims}

In order to contribute to the literature on mathematics teachers' transformation of curriculum materials, the research question considered in this study is as follows: What features of mathematics textbooks are identified by secondary mathematics teachers as worthy of critique? In this study, critiquing means, in particular, the identification of weak elements, including recommendations for improvement.

\section{THEORETICAL BACKGROUND}

\section{Teachers' Critique as a Pivot from their Analysis to Adaptation of Textbooks}

The teacher-curriculum relationship comprises three arenas: design, construction, and mapping (Remillard, 1999). Teachers' critiques of textbooks influence their lesson plans (design) and classroom practices (construction). Moreover, critical analysis of textbooks is achieved through adoption of different perspectives, reasoning about students' learning, and justification with previous teaching experience; thus textbook critique allows teachers to pivot from analysis to adaptation of textbooks.

The textbook features, on which teachers choose to focus, affect their teaching adaptations (Remillard, 2012; Sherin \& Drake, 2009). Moreover, teachers' different approaches to task selection can be traced to their different interpretations of curriculum materials (Remillard, 1999). For example, one teacher may pay particular attention to the exercises, while another may focus on mathematical content. Different foci on the textbook features may also lead to different critiques which would be identified and classified in our study.

The necessity of exploring teachers' critiques is supported by both Atkinson's (2012) study on teachers' critiques of teacher narratives of reflective practice and Davis' (2006) study on preservice science teachers' critiques of curriculum materials. Atkinson (2012) found that "These teachers did not reject reflection as essential and beneficial to teacher growth and development. They found fault with its representation as a decontextualized and autonomous activity." (p. 188), and suggested that "teachers' critiques [should be framed] as informed feedback that needs the inquiry and input of teacher educators" (p. 175). It implied that critiquing can be applied not only for investigating opinions but also for designing reflective practice activities to effectively advance teachers' learning of teaching.

Davis (2006) investigated preservice science teachers' criteria for critiquing instructional materials and classified their criteria into six categories: student ownership and engagement, questioning, instructional goals, real-world application, instructional representations, and communication. Moreover, these teachers less focused on instructional representations and rarely paid attention to how to scaffold children to be successful in scientific inquiry practices. Similarly, this study suggested that teacher education would be supported by critiquing curriculum materials.

Teachers' critiques of textbooks may be related to their past experience and knowledge about mathematics learning and teaching. Lloyd and Behm (2005) have found that "Many (preservice elementary) teachers not only conducted their analyses from the perspective of past experiences with traditional instruction, but they actually applied their expectations so heavily that they sometimes made faulty interpretations of the instructional materials." (p. 58). In view that preservice elementary teachers' experience and knowledge are different from inservice secondary mathematics teachers, it is worth exploring inservice secondary mathematics teachers' critiques of mathematics textbooks. 


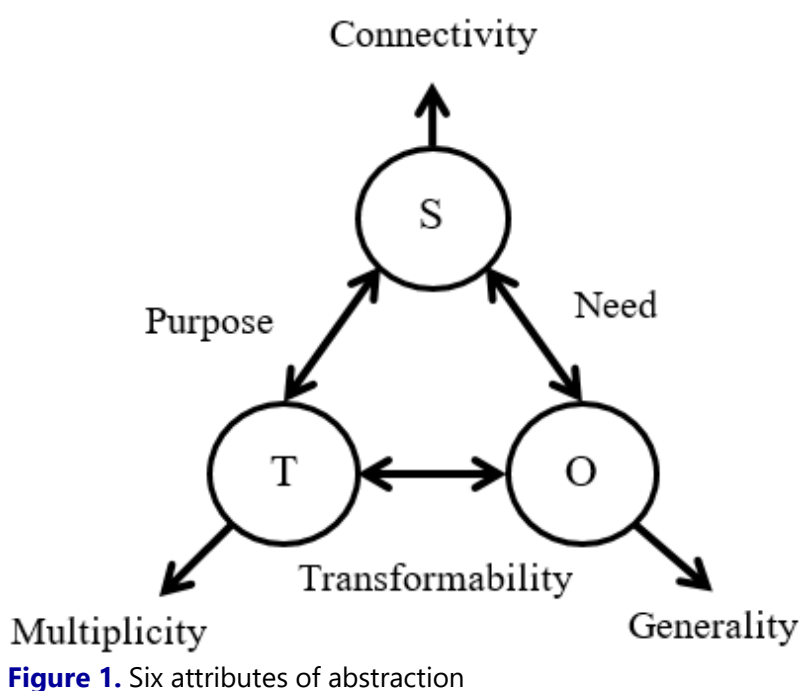

\section{On the Basis of a Framework for Analyzing Mathematics Textbooks}

One model of textbook use presented by Rezat (2006) and one framework of textbook analyses proposed by Yang (2013) are considered to analyze teachers' critiques. According to Rezat's model, the relationship between teacher and textbook is not only interactive but also related to the students and mathematics as a whole. Thus, his model comprises the following four components: teacher, textbook, student and mathematics. Yang's (2013) framework, on the other hand, focuses on analyzing textbooks through the notion of abstraction, identifying three key components: semiotic tools $(\mathrm{T})$, subjects (S), and objects $(\mathrm{O})$. Six attributes are extracted from the three components and their relationships.

Although we agree that the relationship between the teacher and the textbook is transactional on the basis of Rezat's model, the analyses of teachers' textbook use in class is different from the analyses of teachers' critiques. While both teachers and students may be empirical readers in research on teachers' use of textbooks in class, teachers and students are respectively empirical and intended readers in research on teachers' critiques of textbooks (Weinberg, \& Wiesner, 2011). Since students do not really engage in teachers' critiques of textbooks and do not interact with teachers, we started from referring to Yang's (2013) framework in this study.

Abstraction has previously been studied as an essential process in learning mathematics and a key adaptive mechanism of human cognition (Piaget, 1985; von Glasersfeld, 1990). Yang (2013) synthesized the constructiveempirical and the dialectic perspectives on abstraction to define mathematical abstraction as "a mental or social activity through which subjects intentionally identify, reconstruct or apply new mathematical objects represented or mediated by semiotic tools (models, artefacts, or multiple representations)" (p. 36). Figure 1 presents the six attributes and relationships extracted from these components.

The six attributes of abstraction include generality of objects $(\mathrm{O})$, connectivity of subjects (S), multiplicity of semiotic tools (T), subjects' need of objects (S-O), transformability of tools for objects (O-T), and purpose for which subjects use tools (T-S). The generality of objects is related to their connotation and extent of applicability. For instance, the areas of some triangles giving the lengths of bases and heights are less general than the area formula of any triangle. The connectivity of subjects is concerned with the connections made to subjects' experience. For instance, the expression that "When we were in elementary school, we had learned right-angled triangles. For example, the triangle plate which we often use is a right-angled triangle." (Yang, 2013, p. 34), cited from the topic of Pythagoras' theorem in one Taiwanese textbook, implies the aim of connecting the new topic with students' previous relevant knowledge. The multiplicity of semiotic tools is related to types of semiotic tools. In order to well represent the object, semiotic tools must be relevant to the content of the object, such as natural language, geometrical figures and an algebraic formula, which can be all adopted to describe Pythagoras' theorem.

The three other attributes are related to relationships between any two components of abstraction. The subjects' needs for objects are necessary to develop students' understanding of the objects, and may come from cognitive, affective or social needs. For instance, to generate cognitive needs by evoking uncertainty, e.g., conflicts and conjectures (Zaslavsky, 2005), to generate affective needs by using encouraging words, as well as to generate social needs by requiring peer discussion. The transformability of semiotic tools for objects denotes the changes in semiotic tools with respect to the same object. For example, the task asking the subjects to calculate the area of the right-angled triangle giving the lengths of one leg and the hypotenuse requires them to transform the figure of the triangle to the numerical number representing its area. The purpose underlying the relationship between subjects 
Table 1. Three Attributes of Abstraction and their Classifications (Adopted from Yang, 2016)

\begin{tabular}{lll}
\hline Attribute & Description & Operational Classifications \\
\hline Generality & the connotation and the extent of objects G0: specific level \\
& G1: generic level \\
& G2: formal level \\
& G2-1: without proof, G2-2: with proof \\
\hline Connectivity & connections of subjects' experience with CO: no connection \\
objects & C1: more familiar \\
& C2: less familiar \\
\hline Functionality & diagrams used for representing concepts F0: no diagram \\
& or procedures & F1: conceptual diagrams \\
& F1-1: less processing, F1-2: more processing \\
& F2: procedural diagrams \\
& F2-1: less processing, F2-2: more processing \\
& F3: diagrams for presenting the object
\end{tabular}

and semiotic tools are identified as the types of tasks for which subjects use semiotic tools in context. For example, the question of "Do other right-angled triangles possess the same property?" provides the subjects with the purpose of generalizing the property which may prompt them to use both figural and algebraic representations.

Yang (2016) adopted the first three attributes and formulated their operational classification to analyse and compare mathematical textbooks, as shown in Table 1. However, the teaching of mathematics comprises more than abstraction; therefore, Yang's $(2013,2016)$ framework and classification may require further revision and extension for application to the analysis of teachers' critiques.

\section{METHODS}

\section{Context}

This study was conducted in Taiwan, where mathematics textbooks were developed by private publishers who invited university professors and school teachers to collaboratively edit and write the textbooks as an editorial committee. Before the textbooks were published, all of the textbooks were officially evaluated by university professors appointed by the National Academy for Educational Research. The evaluation mainly checked whether the mathematical content in textbooks was correct and involved in the national mathematics curriculum guideline.

\section{Data Collection}

Our data were come from the publisher of textbooks, Nani. One author of this paper was the associate editor of the textbooks, so the publisher admitted to provide the data for research in this study. After the editing of secondary mathematics textbooks was finished, the publisher invited influential and experienced secondary mathematics teachers who were willing to comment on the ready-to-publish textbooks to review the weaknesses and strengths of the textbooks. The rate for accepting the invitation was about $70 \%$ provided by the publisher. Then, the committee discussed whether and how to revise based on these comments.

We acknowledged that the teachers participating in this study did not adequately represent Taiwanese teachers. However, the influential and experienced teachers invited by the publisher to review their textbooks were very likely to have above-average mathematics content knowledge and mathematics pedagogical content knowledge, under the consideration that the publisher aimed to enhance the accessibility of the textbooks and increase marketing of the textbooks. More experienced and knowledgeable teachers may provide more professional critiques.

We analyzed teachers' critiques on the geometric topics, covered three chapters of Book 4 (second semester of grade eight), and three chapters of Book 5 (first semester of grade nigh). In Book 4, the three chapters included (1) plane and geometric figures, (2) properties of triangles, and (3) parallelism and quadrilaterals. In Book 5, the three chapters included (1) proportional segments and similar figures, (2) properties of circles, and (3) proofs and three centers of triangles. In the third chapter of Book 5, there were worked examples of algebra adopted to illustrate reasoning and proof methods. There were two reasons for selecting geometry as the research focus. First, proofs were most commonly introduced through geometric topics in school mathematics. Second, geometry provides a domain for modeling the real world and developing logical structure (Hoyles, 1996). Lastly, Yang's (2016) framework of abstraction has already been applied to analysis of Pythagoras' theorem, a geometric topic. 
The participants of this study were 94 and 49 secondary mathematics teacher who gave their comments on Book 4 and Book 5 respectively. Their comments were collected through being semi-structurally interviewed by executive editors or marketing representatives in group. The main interviewing questions included (1) What were the weaknesses of the textbook overall and why? (2) Which parts of the textbook were not good enough and why? We identified 148 critiques from 94 teachers' comments on Book 4 and 70 critiques from teachers' comments on Book 5 . This method of data collection allowed us with the convenience to investigate a large number of teachers' critiques.

\section{Data Analysis}

Content analysis was used to interpret teachers' critiques and three stages of data analyses were conducted. Directed and conventional content analysis approaches (Hsieh \& Shannon, 2005) were employed in the first two stages respectively. In the third stage, the degree of agreement among coding designations was measured. The details of the three stages were provided as follows.

The directed approach illustrated and validated an initial framework for analysis (Yang, 2013). According to Hsieh and Shannon (2005), a directed approach - guided by an initial framework which can be elaborated or extended - is appropriate when prior research provides a suitable framework for entry, and "help[s] to determine the initial coding scheme or relationships between codes" (p. 1281).

Our focus lays in identifying one key attribute and the main feature as for each critique. That is, we first read each critique and classified it as one of the six attributes originally in Yang's framework (2013). Then, we interpreted its meaning to induce the feature. For instance, a comment on Section 1-2 in Book 5 that "It starts out abstract and moves to less abstract, and this is not good." (B5-221-1) was classified as the attribute of generality and interpreted as the feature of degree of abstractness, which indicated to consider whether the object is abstract, theoretical, complicated, concrete or simple.

If more than one feature was identified, the critique was separated into multiple analysis units. For example, a comment on Section 3-2 in Book 4 (B4-90) was classified into two analysis units: B4-90-1 and B4-90-2.

\footnotetext{
"Let us change back to use compass-and-straightedge construction to elucidate the concept of congruent triangles. Although it would be easier to learn the concept by manipulating the annex (a triangle printed on a transparency), students are less likely to understand it." (B4-90-1).

"If we ask them to draw it (a congruent triangle using compass-and-straightedge construction) once, they can make sense of the concept. Moreover, they learned compass-and-straightedge construction in 2-3, so the content here could act as an application of 2-3." (B4-90-2).
}

The first unit describes the use of semiotic tools, while the second refers to connecting the material with students' prior knowledge. It should be noted here that teachers' critiques did not necessarily depend on appropriate interpretations of the textbook.

In order to check the feasibility of applying Yang's (2013) framework to this analysis and to provide exemplary illustrations for each attribute of abstraction, 31 analysis units were randomly selected for analysis. This preliminary analysis confirmed that Yang's (2013) six attributes of abstraction were not sufficient. Therefore, a conventional approach to content analysis was adopted in the second stage. Critiques were analyzed using a constant comparative method, and these results were used to revise Yang's (2013) six attributes. First, the first author interpreted the analysis units and added a new attribute, teaching practices, in order to classify each of them as one attribute.

Second, the analysis units, which had already been classified into the same attribute, were iteratively compared and contrasted to check whether the meaning of the original attribute was suitable to represent the meaning of these units and to formulate the features underlying each attribute. For instance, as for the attribute of 'generality', two more features were identified: completeness with sufficient variations as well as representativeness of examples, in addition to degree of abstractness. One simplified critique with the feature of completeness with sufficient variations was that "there aren't enough varied problems". One simplified critique with the feature of representativeness of examples or situations was that "the example is not typical of the concept". The detailed critiques would be provided and elaborated in Results.

Third, the first author revised some attributes such that their meanings match the analysis units belonging to them. For instance, the attribute of 'multiplicity of semiotic tools' in Yang's (2013) original framework was revised as the attribute 'accessibility' to cover teachers' concerns over the concreteness of the verbal and nonverbal information provided. In terms of subjects' needs to learn objects, teachers' critiques were mainly focused on the degree of cognitive demand and not on social or affective needs. Thus, "subjects' need of objects" (O-S) was revised 
Table 2. Final coding scheme

\begin{tabular}{|c|c|c|}
\hline $\begin{array}{l}\text { Attributes } \\
\text { (Meaning) }\end{array}$ & Features & Description of Features \\
\hline \multirow{3}{*}{$\begin{array}{l}\text { Generality } \\
\text { (the structure or extension of the } \\
\text { contents and forms of mathematical } \\
\text { objects) }\end{array}$} & degree of abstractness & $\begin{array}{l}\text { to consider whether the object is abstract, } \\
\text { theoretical, complicated, concrete or simple }\end{array}$ \\
\hline & $\begin{array}{l}\text { completeness with sufficient } \\
\text { variations }\end{array}$ & $\begin{array}{l}\text { to consider whether the contents or the structure } \\
\text { of the object is complete with different points of } \\
\text { view or different types of problems }\end{array}$ \\
\hline & $\begin{array}{l}\text { representativeness of examples or } \\
\text { situations }\end{array}$ & $\begin{array}{l}\text { to consider whether examples or situations of } \\
\text { the object are typical representations }\end{array}$ \\
\hline \multirow{2}{*}{$\begin{array}{l}\text { Connectivity } \\
\text { (subjects' prior experience related to } \\
\text { mathematical objects) }\end{array}$} & familiarity & $\begin{array}{l}\text { to evaluate whether students have relevant prior } \\
\text { experience, pre-existing or learnt knowledge }\end{array}$ \\
\hline & alternative conceptions & $\begin{array}{l}\text { to evaluate whether students may understand or } \\
\text { misunderstand }\end{array}$ \\
\hline \multirow{4}{*}{$\begin{array}{l}\text { Accessibility } \\
\text { (the concreteness of verbal and non- } \\
\text { verbal information in texts) }\end{array}$} & syntactic issues & $\begin{array}{l}\text { to notice the length of sentences, sentence } \\
\text { structure, or paragraphing }\end{array}$ \\
\hline & semantic issues & $\begin{array}{l}\text { to notice the explanatory power of sentences or } \\
\text { the clarity of titles }\end{array}$ \\
\hline & figural issues & $\begin{array}{l}\text { to notice issues associated with the attachment } \\
\text { of drawing, pictures, graphs or figures }\end{array}$ \\
\hline & methods of information presentation & $\begin{array}{l}\text { to notice the connection between verbal and } \\
\text { non-verbal information, the highlight of key } \\
\text { ideas, or the necessity of summarization }\end{array}$ \\
\hline \multirow{2}{*}{$\begin{array}{l}\text { Cognitive demands } \\
\text { (the degree to which the subject is } \\
\text { asked to process) }\end{array}$} & to challenge & $\begin{array}{l}\text { to recognize or suggest problems with multiple } \\
\text { solutions or the activity of self-exploration, or to } \\
\text { increase difficulty }\end{array}$ \\
\hline & to support & $\begin{array}{l}\text { to recognize or suggest detailed solutions or } \\
\text { instruction, or to decrease the difficulty }\end{array}$ \\
\hline \multirow[t]{2}{*}{$\begin{array}{l}\text { Transformability } \\
\text { (the changes in modes of } \\
\text { representations) }\end{array}$} & resources for learning & $\begin{array}{l}\text { to consider whether to provide opportunities for } \\
\text { students to use learning materials, e.g. } \\
\text { straightedge and compass, paper folding, } \\
\text { drawing }\end{array}$ \\
\hline & resources for teaching & $\begin{array}{l}\text { to consider whether to provide teachers with } \\
\text { teaching aids or technological tools }\end{array}$ \\
\hline \multirow{3}{*}{$\begin{array}{l}\text { Purposes } \\
\text { (types of learning activities) }\end{array}$} & reproduction & $\begin{array}{l}\text { to suggest an increase or decrease of exercises, } \\
\text { same types of questions, or learning by imitation }\end{array}$ \\
\hline & justification & $\begin{array}{l}\text { to suggest an increase or decrease of activities of } \\
\text { generating, comparing, or testing with examples, } \\
\text { or judging validity }\end{array}$ \\
\hline & application & $\begin{array}{l}\text { to suggest an increase or decrease of application } \\
\text { questions, e.g. mathematical questions, real-life } \\
\text { or situational questions }\end{array}$ \\
\hline \multirow[t]{4}{*}{$\begin{array}{l}\text { Teaching practices } \\
\text { (features related to teachers' habits, } \\
\text { beliefs, and knowledge) }\end{array}$} & time & to address the issue of instructional time \\
\hline & $\begin{array}{l}\text { teaching habits and beliefs in relation } \\
\text { to tools }\end{array}$ & $\begin{array}{l}\text { to address teachers' familiarity with the } \\
\text { instruments, the forms of expressions, or } \\
\text { conventional methods }\end{array}$ \\
\hline & $\begin{array}{l}\text { teaching habits and beliefs in relation } \\
\text { to objects }\end{array}$ & $\begin{array}{l}\text { to address teachers' conceptions of content, } \\
\text { definition, structure, rigor }\end{array}$ \\
\hline & knowledge for teaching & to disclose teachers' own misunderstandings \\
\hline
\end{tabular}

as "cognitive demands". Then, the first author reread the 31 randomly selected units to rearticulate the meaning of each revised attribute.

Lastly, the second author and a mathematics teacher with a master's degree in mathematics education collectively applied the revised coding scheme to analysis of another 30 units. This was to verify that the revised coding scheme was understandable and provided a comprehensive framework for analysis. They pointed out that the meanings of some features were not clear, and some units could not be classified into a single feature within the revised scheme. The first author proposed new features (e.g., methods of information presentation as well as knowledge for teaching) to categorize the unclassified units. The final coding scheme applied to analysis of all 274 units is shown in Table 2. 
In the third stage, the degree of agreement among codings was measured. Another mathematics teacher, studying for his masters degree in mathematics education, was trained in the coding scheme through analysis of 21 units, and then asked to apply the scheme to another 51 units, focusing in particular on the classification of each unit to one key attribute. The rate of agreement between this teacher and the second author were $86.2 \%$. Disagreements were further discussed by the two authors until a unanimous decision was reached on classification of these differing codes. Remaining analysis units were coded by the second author.

At this point we must clarify certain methodological issues. First, we recognize the limitations of the data collected in the context of this study. The results cannot be generalized; however, these critiques provide a window into teachers' cognition and beliefs on learning and teaching. Second, as the critiques are constrained by the extent of their willingness, cognition and beliefs toward learning and teaching cannot be comprehensively identified. The attributes and features identified in these critiques therefore cannot be extended to imply anything related to the participating teachers' classroom practices.

\section{RESULTS}

Table 3 shows the percentages of attributes and features identified from teachers' critiques. As different teachers provided different numbers of critiques, we cannot claim that each teacher equally contributed to data collection. However, analysis of the critiques reveals a diversity of attributes and features that can be further analyzed in terms of relative frequencies. The data indicates that the attribute 'teaching practices' appeared most frequently $(26.6 \%)$; and the second-most frequent were 'generality and accessibility' $(19.7 \%)$. In sum, $66 \%$ of the critiques were related to teaching practice, generality, and accessibility, and the attributes of connectivity and transformability appeared the least. That is, teaching habits, beliefs and knowledge, the structure or extension of the contents, the forms of mathematical objects, and the concreteness of verbal as well as non-verbal information appeared more frequently than subjects' experience related to mathematical objects, and changes in modes of representations.

Table 3 also shows the distribution of features within attributes. The data indicated that these critiques focused mostly on the feature of completeness with sufficient variations (13.8\%) in the attribute of generality, and secondly on the feature of teaching habits or beliefs in relation to objects $(10.9 \%)$ as well as tools $(9.8 \%)$ in the attribute of teaching practices. For the attribute of purposes, teachers suggested only the purpose of reproduction might be decreased $(1.5 \%)$. No critique suggested decreasing justification and application. Although these results cannot be generalized to other contexts, this distribution does provide evidence from which to infer which attributes and features are considered most important in curriculum materials, and to guide an investigation of the underlying reasons for this ranking. 
Table 3. Distribution of attributes and features underlying teachers' critiques

\begin{tabular}{|c|c|c|c|}
\hline Attributes & $\begin{array}{l}\text { Features } \\
\text { (Exemplary simplified critique) }\end{array}$ & Percentages (\%) & Subtotal (\%) \\
\hline \multirow{4}{*}{ Generality } & $\begin{array}{l}\text { degree of abstractness } \\
\text { (It is too theoretical to understand.) }\end{array}$ & 4.4 & \multirow{4}{*}{19.7} \\
\hline & completeness with sufficient variations & & \\
\hline & $\begin{array}{l}\text { (Using this exploratory activity to introduce the discrimination of } \\
\text { parallel lines by proportional segments is not sufficient.) }\end{array}$ & 13. 8 & \\
\hline & $\begin{array}{l}\text { representativeness of examples } \\
\text { (It is not typical of the concept.) }\end{array}$ & 1.5 & \\
\hline \multirow{2}{*}{ Connectivity } & $\begin{array}{l}\text { familiarity } \\
\text { (I think students are unfamiliar with it.) }\end{array}$ & 1.1 & \multirow{2}{*}{2.9} \\
\hline & $\begin{array}{l}\text { alternative conceptions } \\
\text { (Students have alternative concepts.) }\end{array}$ & 1.8 & \\
\hline \multirow{4}{*}{ Accessibility } & $\begin{array}{l}\text { syntactic issues } \\
\text { (The description is too long.) }\end{array}$ & 3.3 & \multirow{4}{*}{19.7} \\
\hline & $\begin{array}{l}\text { semantic issues } \\
\text { (The phrase could be difficult to understand.) }\end{array}$ & 2.2 & \\
\hline & $\begin{array}{l}\text { figural issues } \\
\text { (The figure may mislead students.) }\end{array}$ & 7.3 & \\
\hline & $\begin{array}{l}\text { methods of information presentation } \\
\text { (To add a focus frame after an example.) }\end{array}$ & 6.9 & \\
\hline \multirow{2}{*}{ Cognitive demands } & $\begin{array}{l}\text { to challenge } \\
\text { (To make it more difficult.) }\end{array}$ & 5.1 & \multirow{2}{*}{13.5} \\
\hline & $\begin{array}{l}\text { to support } \\
\text { (To make it less difficult.) }\end{array}$ & 8.4 & \\
\hline \multirow{2}{*}{ Transfor-mability } & $\begin{array}{l}\text { resources for learning } \\
\text { (The resource is not helpful for students.) }\end{array}$ & 2.2 & \multirow{2}{*}{2.6} \\
\hline & $\begin{array}{l}\text { resources for teaching } \\
\text { (The resource is not useful for teachers.) }\end{array}$ & 0.4 & \\
\hline \multirow{4}{*}{ Purposes } & $\begin{array}{l}\text { to increase reproduction } \\
\text { (Simple exercises are necessary.) }\end{array}$ & 1.5 & \multirow{4}{*}{9.2} \\
\hline & $\begin{array}{l}\text { to decrease reproduction } \\
\text { (To provide various worked examples.) }\end{array}$ & 1.5 & \\
\hline & $\begin{array}{l}\text { to increase justification } \\
\text { (To ask students to explain their judgments.) }\end{array}$ & 1.5 & \\
\hline & $\begin{array}{l}\text { to increase application } \\
\text { (More questions are needed to apply what have been learnt.) }\end{array}$ & 4.7 & \\
\hline \multirow{4}{*}{ Teaching practices } & $\begin{array}{l}\text { time } \\
\text { (Content is too much to teach well.) }\end{array}$ & 3.3 & \multirow{4}{*}{26.6} \\
\hline & $\begin{array}{l}\text { in relation to tools } \\
\text { (The transparencies are not appropriate.) }\end{array}$ & 9.8 & \\
\hline & $\begin{array}{l}\text { in relation to objects } \\
\text { (The content sequence is not proper.) }\end{array}$ & 10.9 & \\
\hline & $\begin{array}{l}\text { Knowledge } \\
\text { (The solution is not correct.) }\end{array}$ & 2.6 & \\
\hline Miscellaneous & ("I do not like the picture.") & 5.8 & 5.8 \\
\hline
\end{tabular}

In the following, we consider several examples to further illustrate significant features identified in the critiques. In terms of the generality of the object, three features were highlighted: abstractness, completeness with sufficient variations, and representativeness. A significant portion of the teachers critiqued the arrangement of the contents from more to less abstract. For instance, "it starts out abstract and moves to less abstract, and this is not good" (B5221-1). Another exemplary critique of this feature was "it is too theoretical to understand" (B5-206-3).

'Completeness with sufficient variations' concerns whether the contents or the structure of one object is presented from enough different points of view or a sufficient number of different types of problems are offered. Teachers seem to expect a comprehensive presentation of an object in textbooks. For instance, as shown in Figure 2, B4-46 commented that "there aren't enough varied problems, for instance, Worked examples 2 and 3 are similar, just different situations". This indicates that teachers may compare worked examples in terms of mathematical content rather than structure or scenario. Therefore, certain teachers may pay more attention to the object (the area, the size of the angle, the length of the arc) than to the relationship between the subject and the semiotic tools 


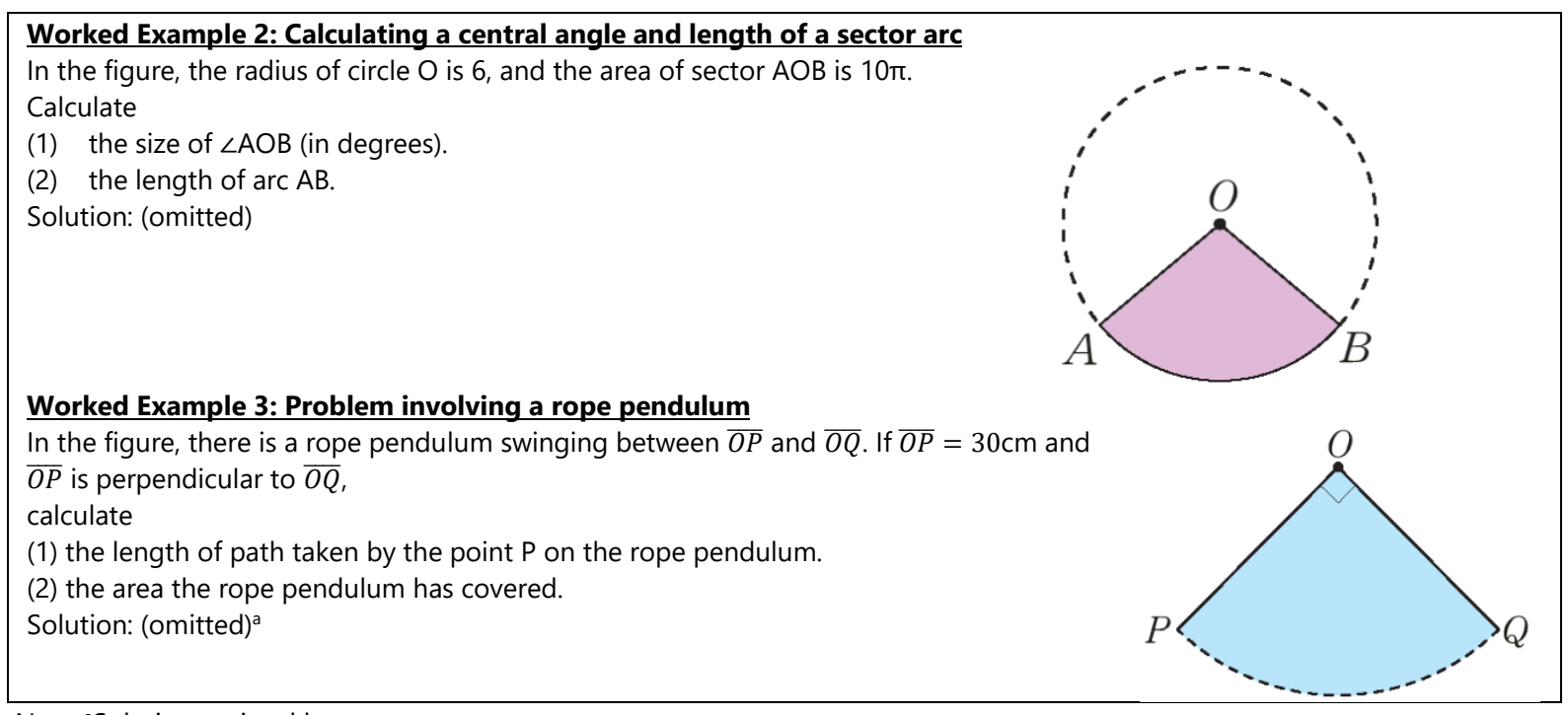

Note. aSolution omitted here to save space

Figure 2. Text critiqued by B4-46

\begin{tabular}{|c|c|c|}
\hline \multicolumn{3}{|l|}{ Worked Example 7: Using the exhaustive method } \\
\hline \multirow{5}{*}{$\begin{array}{l}\text { Given that } a \text { and } b \text { are positive integers, and } a \times b \text { is an even integer, } \\
\text { prove that } a \text { or } b \text { is an even integer. }\end{array}$} & $(a, b)$ & $a \times b$ \\
\hline & (even, even) & even \\
\hline & (even, odd) & even \\
\hline & (odd, even) & even \\
\hline & (odd, odd) & odd \\
\hline
\end{tabular}

Figure 3. Text critiqued by B5-235

(reproduction or application). Worked examples 2 and 3 can be viewed as reproduction and application tasks respectively because the former is part of a mathematical context and the latter falls under a real-world context.

Another example of completeness with sufficient variations is that "Using this exploratory activity to introduce the discrimination of parallel lines by proportional segments is not sufficient, and it is critical to ask students whether proportional segments necessarily result in parallel lines." (B-5-180-1). It indicates that teachers expect that mathematics textbooks can provide critical questions to prevent students from overgeneralizing a property.

Representativeness concerns whether examples or contexts supplied are typical representations of the object. For instance, B5-235 critiqued the content shown in Figure 3, commenting that “... It was not a typical example [for teaching the exhaustive method].... $|\mathrm{a}|+|\mathrm{b}|=0$ is a better example". Through informal discussion with other teachers who also agreed that the worked example is not typical, two possible reasons were proposed to explain why it is not typical. One is that the situation can be connected to both the trichotomy law and the concept of absolute values, and the other is that students may easily understand the conclusion of the situation where only one case is valid. This indicates that teachers judge examples based on their connections to broader topics within mathematics and on their representativeness. Similar concerns were identified in Zodik and Zaslavsky's (2008) study into teachers' choice of examples.

In terms of connectivity, two features were highlighted: (un)familiarity and alternative conceptions. For instance, B4-53 provided a critique of the content, as shown in Figure 4: "I heard that other teachers found the worked example difficult. On the basis of my practical teaching, I think students are unfamiliar with sectors and their properties." 


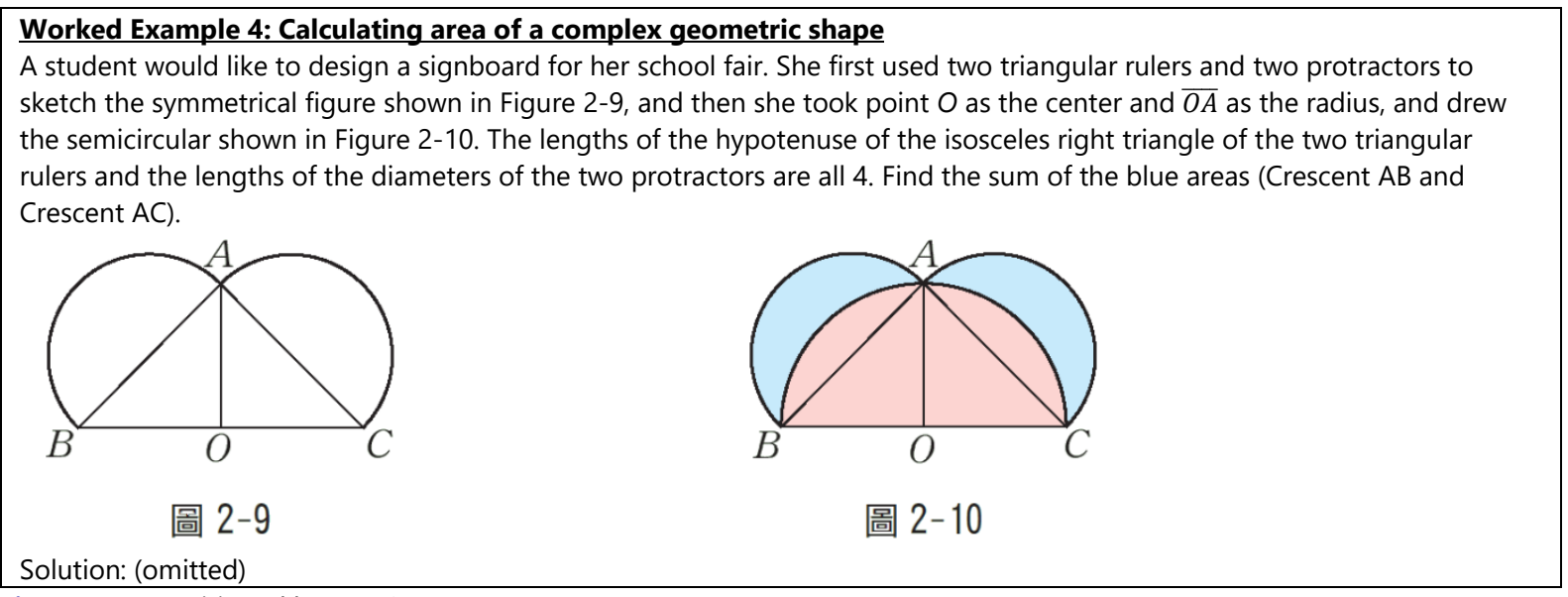

Figure 4. Text critiqued by B4-53

\section{Discovery Activity: center of circumscribed circle}

In the figure, circle $O$ is a circumscribed circle of quadrilateral $A B C D$, and point $O$ is the center of circumscribed circle. Then,

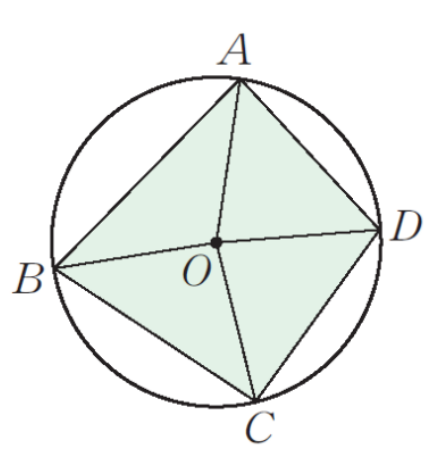

(1) Are the lengths of $\overline{A O}, \overline{B O}, \overline{C O}$ and $\overline{D O}$ equal? Solution (omitted)

(2) Is point $O$ on the perpendicular bisector of segment $\overline{A B}$ ? Solution (omitted)

(3) Is point $O$ the intersection of the four perpendicular bisectors of the four segments of quadrilateral $A B C D$ ? Solution (Omitted)

Figure 5. Text critiqued by B5-241

Alternative conceptions concern whether the subject's preconceptions of the object are suitably taken into account. For instance, the discovery activity shown in Figure 5 asks the student to prove that point $\mathrm{O}$, the circumcenter of the polygon, is the intersection of all the perpendicular bisectors of all the sides of the polygon. B5241 provided the following critique:

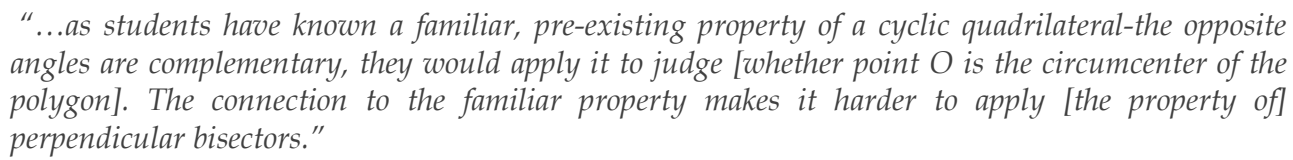

It could be that the teacher misunderstood the purpose of this discovery activity, because applying the property that opposite angles are complementary is not an appropriate response to questions (2) and (3). Alternatively, the teacher might be of the opinion that students' familiarity with one property of the object may inhibit their discovery of another property of the same object.

In terms of accessibility of the semiotic tool, four features were identified: syntactic issues, semantic issues, figural issues and methods of information presentation. Syntactic issues concern the length of a sentence, sentence structure, or paragraphing. For instance, B4-77 suggested that "the description of the content should be more concise and shorter because students tend to be less interested in long explanations". B5-208-1 commented that "most of the descriptions in the textbook are too lengthy".

Semantic issues concern whether the wording of explanations is understandable. For instance, B5-186 commented that 'the phrase "shrink-enlarge for k times" could be difficult to understand'. The words 'shrinkenlarge' can be more explicitly explained as zooming out and in. B4-77 suggested providing an explanation for the first step of the solution for one problem. These critiques indicate that it is beneficial to replace contracted words with simple words or to provide the reasons underlying certain conditions. 


\section{Worked Example 1: Range of third side of triangle}

A triangle has sides of lengths $a, 5$ and 8. Find the range of $a$.

Solution: (omitted)

Figure 6. Text critiqued by B4-119

\section{Discovery Activity: SAS compass-and-straight-edge construction}

1. Complete Steps 1 to 4 :

(1) Take out Annex (3), $\triangle A B C$ printed on a transparency,

and check whether or not $\angle B$ and $\angle E$ overlap completely.

(2) Take point $E$ as the center, the length of $\overline{A B}$ as the radius to construct an arc that intersects one side of $\angle E$ at the point $D$.

(3) Take point $E$ as the center, the length of $\overline{B C}$ as the radius to construct an arc that intersects another side of $\angle E$ at the point $F$.

(4) Join $\overline{D F}$ to form the triangle $\triangle D E F$.

2. Do $\triangle A B C$ and $\triangle D E F$ overlap completely?

Figure 7. Text critiqued by $\mathrm{B} 4-78$

Figural issues concern whether figures are sufficient, dynamic, and functional. For instance, B4-149 suggested that "The general figure may mislead students. A counterexample might help students to discover that it's incorrect." This critique indicates that it is better to give figures as obvious counterexamples rather than general examples that require processing when students are asked to refute one incorrect property. It implies that the teacher might hold an expectation of textbooks as a supporter rather than initiator of students' thought processes.

Methods of information presentation concern the sequence, layouts and appearance of information. For instance, B4-160 suggested adding a 'focus frame' after a worked example to identify its salient points. B4-115 suggested providing a description of the converse of the hinge theorem in addition to a 'focus frame'.

In terms of cognitive demands, the teachers were concerned with how to increase or decrease the degree to which the subject is asked to process, and about how to provide ways to make the object more difficult or easier to learn. Thus, two features were identified: making it easier to challenge and making it less difficult to support. For instance, B4-119 provided the following critique of the content shown in Figure 6: "it was too soon to use algebraic symbols in the first worked example" and suggested "adopt[ing] numerical examples, for instance, the first exercise on page 129."

In terms of transformability, two features were highlighted: resources for learning and for teaching. Some teachers suggested providing manipulative materials, for example, transparencies, grid papers, or compasses. Their critiques can be classified into two kinds: semiotic tools for use by students or teachers. The majority of these critiques were related to students' use of semiotic tools. For instance, B4-78 provided a critique of the content shown in Figure 7, commenting that "It is not good to provide one angle in a transparency for students to explore SAS properties. It is better to ask students to construct a triangle using a compass and a straightedge under the condition of SAS."

In terms of purposes, three features were highlighted: reproduction, justification, and application. These features are related to ways in which students learn mathematics. Reproduction concerns student drills: for example, exercises that differ from the worked examples. Although teachers may see value in providing exercises that are similar to worked examples, they still suggest providing various worked examples in order to prevent too much imitative learning. Justification concerns whether students are asked to make judgments through testing, generating, or comparing examples.

Application concerns whether sufficient questions are provided for the subject to apply the object. For instance, B4-170 provided a critique of the content shown in Figure 8, commenting that "the exploratory activity wasn't followed up by a problem that could be solved by applying the explored property" and suggested "add[ing] one more problem to apply the property, like the Worked Example 5 following the above exploratory activity". This comment implies that applied problems are not only adopted for perceiving the usefulness of mathematics but also for becoming familiar with mathematics. 


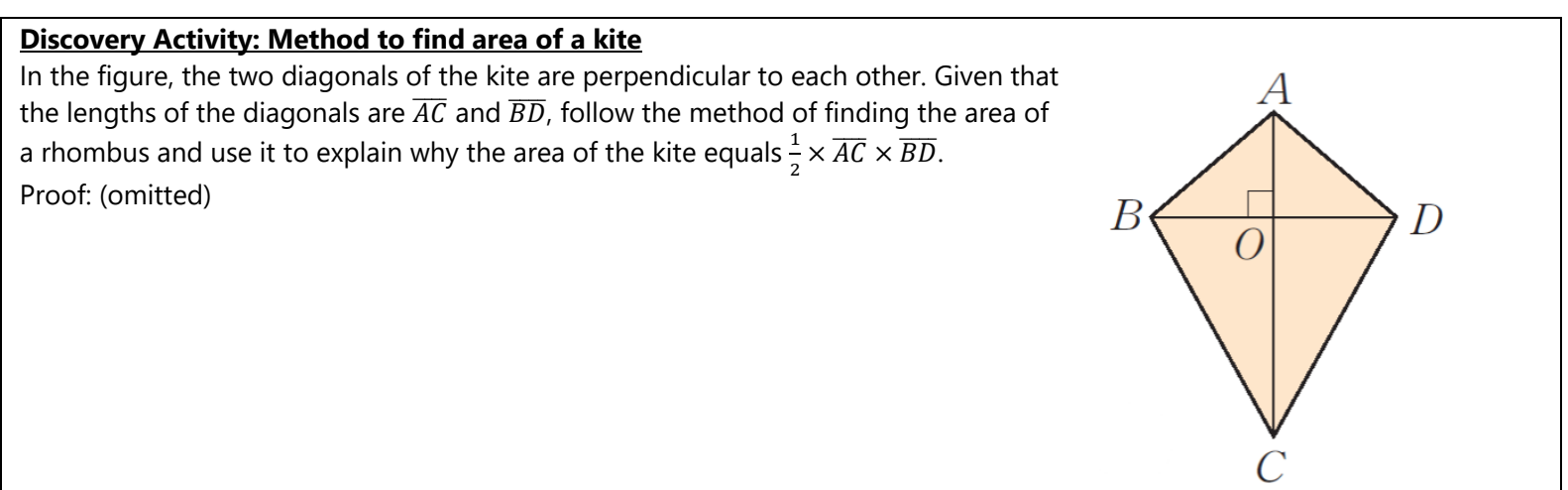

Figure 8. Text critiqued by B4-170

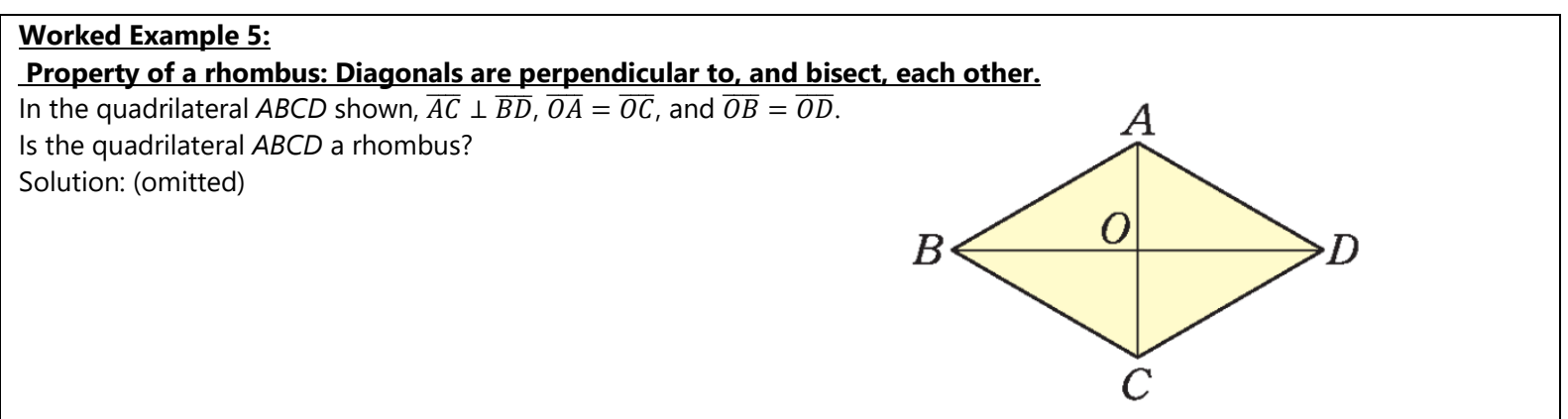

Figure 9. Worked example referenced by B4-170

In terms of teaching, teachers' critiques were related to their own practices, beliefs, and knowledge. Examples of comments are as follows:

\section{"There is too much in this section. It can't be taught in a limited time." (B5-214) \\ "I do not like transparencies, and I'm used to using traditional geometric constructions." (B4-99)}

Moreover, alternative concepts held by teachers were revealed. For instance, B4-66 said "the sum of angles of any triangle should start from the sum of exterior to interior angles of any triangle". This comment implies that the teacher might not follow the logical structure of Euclidean geometry, assuming that local reasoning from the sum of exterior to interior angles of a triangle is a more sensible approach for students.

\section{DISCUSSION}

In this paper, we aim to investigate which features of mathematics textbooks are highlighted in mathematics teachers' critiques. The results show that most features are related to the attribute of teaching practice, and of least concern is the attributes of connectivity and transformability. These teachers' concerns with the generality of objects and the accessibility of semiotic tools are only second to teaching practices. This implies that Taiwanese mathematics teachers may be concerned about whether textbooks provide sufficient opportunities to learn the generality of mathematics via accessible representations. The generality of mathematics involves the features of abstractness, completeness with sufficient variations, and representativeness, while accessible representations involve syntactic, semantic, and figural issues, as well as methods of information presentation. This finding not only supports the idea that East-Asian mathematics teachers stress knowledge structure in their teaching of mathematics (Bryan, Wang, Perry, Wong, \& Cai, 2007), but also emphasizes accessible representations as a feature of effective teaching.

The four most frequently noticed features included (1) completeness with sufficient variations (to consider whether the contents or the structure of the object is complete with different points of view or different types of problems); (2) teachers' habits and beliefs in relation to objects (to address teachers' conceptions of content, definitions, structure, rigor); (3) teaching habits and beliefs in relation to tools (to address teachers' familiarity with the instruments, the forms of expressions, or teachers' conventional methods); (4) cognitive support (to increase or to decrease the difficulty). The first feature belongs to generality, while the second and third features belong to 
teaching practices. The fourth is a feature of cognitive demands. That is, teachers are also concerned about the difficulty of the content or examples apart from the generality of objects and teaching practices.

Jacobs, Yoshida, Stigler, and Fernandez (1997) have provided empirical evidence that teachers' beliefs about learning and teaching can be inferred from their critiques of videotaped lessons. Rezat (2009) suggested to generalize Vergnaud's notion of theorems-in-action and concepts-in-action to the notion of beliefs-in-action. The appendix 'in-action' can be adopted to underline that beliefs are intertwined with actions, i.e. critiques in this study. Pepin, Gueudet and Trouche (2013) further pointed out that most studies investigating teacher-resource interactions where teachers' beliefs shaped their use of the curriculum materials, and the features of the curriculum materials could 'produce' an evolution in teachers' beliefs. Although beliefs-in-critiques are not a direct aim of this study, we further infer teachers' beliefs underlying their critiques in the following discussion.

Some teachers critiqued the abstractness of certain sections of the reviewed chapters, which indicated an underlying belief that the mathematical content should be described less theoretically. Some teachers critiqued the completeness of the descriptions, indicating a belief that sufficient variations are key to discerning the invariant aspects of an object. Interestingly, only a small percentage of the teachers in this study highlighted transformability, which is helpful to discerning mathematical concepts based on the variation theory of learning (Koichu, Zaslavsky, \& Dolev, 2016). Teachers' critiques of typical examples may imply the existence of a belief that the critical mathematical connection to students' experience forms part of the representativeness of the object. Moreover, B4119 's critique indicated a belief in the superiority of numerical examples before algebraic examples. This idea was also supported by the critique of B5-221-1, who focused on the abstract nature of the example. B4-78's comment indicated a belief that complete manipulation is more effective than partial manipulation in geometric construction. These possible underlying beliefs suggest researchers to investigate to what extent complete and partial constructions affect students' visualization and reasoning in geometry (Duval, 1998).

The critiques focusing on the features of reproduction and justification indicated two possible underlying beliefs. One is that providing various worked examples can prevent imitative learning, and the other is that justifying is a way to make sense of properties. The coexistence of these two beliefs echo the link between transmission by the use of worked examples and inquiry where justification is one key process in learning mathematics (Godino, Batanero, Cañadas, \& Contreras, 2017). In this study, possible beliefs are inferred in terms of the quality of mathematics textbooks. A fruitful direction for future research could be comparison of beliefs inferred from teachers' responses to questionnaires, their evaluations of textbooks and teaching in practice. This has the potential to shed light on the inconsistencies between teachers' beliefs and practice.

Research on teachers' noticing highlights teachers' reflections on what happens in the complexity of practical teaching (e.g., Artzt, Armour-Thomas, Curcio \& Gurl, 2015) and videoed teaching (e.g., Colestock \& Sherin, 2009). Several studies have adopted the construct of teachers' noticing to unpack teachers' observations of classroom practice (Sherin, Jacobs \& Philipp, 2011). Similarly, teachers' critiques of textbooks can be analyzed by cataloguing the features that teachers are concerned about to highlight significant noticing. Previous studies have classified the features identified by teachers as content-related (e.g., "using those parameters to write the general form of the exponential equation"), student-related (e.g., "reduce demand of tasks"), and teacher-related (e.g., "save time") (Choppin, 2011, p. 340). Our study extends these works by providing both more categories of attributes and features.

Two other extensions of this study are worthy of further consideration: (a) what strategies effectively improve mathematics teachers' critiques of textbooks, and (b) how mathematics teachers' critiques of textbooks influence their adaptation of textbooks. The findings of this study, together with these extensions, call for the incorporation of adequate preparation within teacher education and professional development for the critique of curriculum materials.

\section{CONCLUSIONS}

This study justifies the classification of teachers' critiques of mathematics textbooks into the following seven attributes: generality, connectivity, accessibility, cognitive demands, transformability, purposes, and teaching practices. The attributes in this study have been modified from those proposed in Yang's (2016) study on textbook analysis through extension of Yang's (2013) notion of abstraction.

Although several previous studies have investigated how mathematics teachers analyze and interpret instructional materials (e.g. Choppin, 2011; Lloyd \& Behm, 2005), there is little information concerning which features of curriculum materials are noticed by teachers in their critiques of these materials. The findings of this study not only deepen our understanding of which features related to objects, subjects, semiotic tools and their relationships teachers highlight, but also provide methodological and educative implications.

In this study, the data were collected by asking teachers to comment on the weakness and strengths of mathematics textbooks, which can be viewed as part of teachers' documentation work: looking for resources, 
selecting mathematical tasks, and managing available artifacts (Gueudet \& Trouche, 2009), and then analyzed to infer teachers' beliefs. The rationale that teachers' critiques of textbooks can reveal their beliefs is based on Vergnaud's (1998) notion of concepts-in-action and theorems-in-action, which could be inferred from analyzing teachers' documentation work (Gueudet \& Trouche, 2009). Although this study does not provide any direct evidence of teachers' beliefs, it does supply indications of items suitable for measuring teachers' beliefs about the quality of mathematics textbooks, which they enact in critique of these textbooks.

In terms of teacher education, these modified attributes can be used to develop probing questions in the facilitation of pre-service teachers' analysis of curriculum materials. This would support the development of proficiency in critiquing curriculum materials, as proposed in the study of Beyer and Davis (2012) for the training of science teachers. Just as observation of videoed teaching practice has been recommended (Star \& Strickland, 2008; Van Es, \& Sherin, 2002), analysis of the different features of textbooks may serve as a means to improve the skills of pre-service teachers.

One main limitation of the findings in this study was that the collected teachers' critiques were influenced by the quality of the textbooks. The textbooks used in this study were edited by two mathematics education professors, two mathematics professors, three senior high school teachers and four junior high school teachers. Since the authors of the textbooks were deliberately invited by the publisher and qualified, the quality of textbooks could be assumed to be above an acceptable level. Moreover, when criticizing the textbooks, the mathematics teachers might heavily rely on their own teaching experience to evaluate the strengths and weaknesses of the textbooks. Thus, the diversity of the features found in this study may be limited. Nevertheless, the results of this study provided the possible attributes and features which the mathematics teachers were concerned about when critiquing textbooks.

\section{ACKNOWLEDGEMENTS}

We thank the reviewers for their helpful comments and suggestions. This study was supported by the Ministry of Science and Technology of Taiwan under Grant NSC 101-2511-S-003-010-MY3 and MOST 107-2511-H-003-004MY3.

\section{REFERENCES}

Artzt, A. F., Armour-Thomas, E., Curcio, F. R., \& Gurl, T. J. (2015). Becoming a reflective mathematics teacher: A guide for observations and self-assessment. New York: Routledge. https:/ / doi.org/10.4324/9781315776941

Atkinson, B. M. (2012). Rethinking Reflection: Teachers' Critiques. The Teacher Educator, 47(3), 175-194. https:/ / doi.org/10.1080/08878730.2012.685796

Beyer, C. J., \& Davis, E. A. (2012). Learning to critique and adapt science curriculum materials: Examining the development of preservice elementary teachers' pedagogical content knowledge. Science Education, 96(1), 130-157. https:// doi.org/10.1002/sce.20466

Bryan, C. A., Wang, T., Perry, B., Wong, N. Y., \& Cai, J. (2007). Comparison and contrast: similarities and differences of teachers' views of effective mathematics teaching and learning from four regions. ZDM, 39(4), 329-340. https://doi.org/10.1007/s11858-007-0035-2

Charalambous, C. Y., \& Hill, H. C. (2012). Teacher knowledge, curriculum materials, and quality of instruction: Unpacking a complex relationship. Journal of Curriculum Studies, 44(4), 443-466. https:/ / doi.org/10.1080/00220272.2011.650215

Choppin, J. (2011). Learned adaptations: Teachers' understanding and use of curriculum resources. Journal of mathematics teacher education, 14(5), 331-353. https:/ / doi.org/10.1007/s10857-011-9170-3

Colestock, A., \& Sherin, M. G. (2009). Teachers' sense-making strategies while watching video of mathematics instruction. Journal of Technology and Teacher Education, 17(1), 7-29.

Davis, E. A. (2006). Preservice elementary teachers' critique of instructional materials for science. Science Education, 90(2), 348-375. https:// doi.org/10.1002/sce.20110

Drake, C., \& Sherin, M. G. (2009). Developing curriculum vision and trust. Mathematics teachers at work: Connecting curriculum materials and classroom instruction, 321-337.

Duval, R. (1998). Geometry from a cognitive point of view. In C. Mammana \& V. Villani (Eds.), Perspectives on the teaching of geometry for the 21st century: An ICMI study (pp. 37-52). Dordrecht: Kluwer.

Godino, J. D., Batanero, C., Cañadas, G. R., \& Contreras, J. M. (2017). Linking inquiry and transmission in teaching and learning mathematics and experimental sciences. Acta Scientiae, 18(4).

Gueudet, G., \& Trouche, L. (2009). Towards new documentation systems for mathematics teachers? Educational Studies in Mathematics, 71(3), 199-218. https:/ / doi.org/10.1007/s10649-008-9159-8 
Hoyles, C. (1996). Modelling Geometrical Knowledge: The Case of the Students. Nato Asi Series F: Computer and System Sciences, 117, 94-112. https:/ / doi.org/10.1007/978-3-642-60927-5_7

Hsieh, H. F., \& Shannon, S. E. (2005). Three approaches to qualitative content analysis. Qualitative Health Research, 15(9), 1277-1288. https:/ / doi.org/10.1177/1049732305276687

Jacobs, J. K., Yoshida, M., Stigler, J. W., \& Fernandez, C. (1997). Japanese and American teachers' evaluations of mathematics lessons: A new technique for exploring beliefs. The Journal of Mathematical Behavior, 16(1), 7-24. https://doi.org/10.1016/S0732-3123(97)90004-3

Koichu, B., Zaslavsky, O., \& Dolev, L. (2016). Effects of variations in task design on mathematics teachers' learning experiences: a case of a sorting task. Journal of Mathematics Teacher Education, 19(4), 349-370. https:/ / doi.org/10.1007/s10857-015-9302-2

Lloyd, G. M., \& Behm, S. L. (2005). Preservice elementary teachers' analysis of mathematics instructional materials. Action in Teacher Education, 26(4), 48-62. https:/ / doi.org/10.1080/01626620.2005.10463342

Lloyd, G., Remillard, J. T., \& Herbel-Eisenmann, B. (2009). Teachers' use of curriculum materials: An emerging field. In J. T. Remillard, B. Herbel-Eisenmann, \& G. Lloyd (Eds.), Mathematics teachers at work: Connecting curriculum materials and classroom instruction (pp. 3-14). New York: Routledge.

Nicol, C. C., \& Crespo, S. M. (2006). Learning to teach with mathematics textbooks: How preservice teachers interpret and use curriculum materials. Educational Studies in Mathematics, 62(3), 331-355. https:/ / doi.org/10.1007/s10649-006-5423-y

Pepin, B., Gueudet, G., \& Trouche, L. (2013). Re-sourcing teachers' work and interactions: A collective perspective on resources, their use and transformation. ZDM, 45(7), 929-943. https:/ / doi.org/10.1007/s11858-013-05342

Piaget, J. (1985). The equilibration of cognitive structures: The central problem of intellectual development. Chicago: University of Chicago Press.

Remillard, J. (2005). Examining key concepts in research on teachers' use of mathematics curricula. Review of Educational Research, 75(2), 211-246. https:/ / doi.org/10.3102/00346543075002211

Remillard, J. (2012). Modes of engagement: Understanding teachers' transactions with mathematics curriculum resources. In G. Gueudet, B. Pepin, \& L. Trouche (Eds.), From text to 'lived' resources: Mathematics curriculum materials and teacher development (pp. 105-122). New York: Springer. http://doi.org/10.1007/978-94-0071966-8_6

Remillard, J. T. (1999). Curriculum materials in mathematics education reform: A framework for examining teachers' curriculum development. Curriculum Inquiry, 29(3), 315-342. https://doi.org/10.1111/03626784.00130

Rezat, S. (2006). A model of textbook use. In J. Novotná, H. Moraová, M. Krátká, \& N. Stehlíková (Eds.), Proceedings 30th Conference of the International Group for the Psychology of Mathematics Education (Vol. 4, pp. 409-416). Prague, Czech Republic: PME.

Rezat, S. (2009). The utilization of mathematics textbooks as instruments for learning. In V. Durand-Guerrier, S. Soury-Lavergne, \& F. Arzarello (Eds.), Proceedings of the Sixth Congress of the European Society for Research in Mathematics Education (pp. 1260-1269). Lyon, France: INRP.

Sherin, M. G., \& Drake, C. (2009). Curriculum strategy framework: investigating patterns in teachers' use of a reform-based elementary mathematics curriculum. Journal of Curriculum Studies, 41(4), 467-500. https:/ / doi.org/10.1080/00220270802696115

Sherin, M. G., Jacobs, V. R., \& Philipp, R. A. (Eds.). (2011). Mathematics teacher noticing: Seeing through teachers' eyes. New York, NY: Routledge. https:/ / doi.org/10.4324/9780203832714

Star, J. R., \& Strickland, S. K. (2008). Learning to observe: Using video to improve preservice mathematics teachers' ability to notice. Journal of mathematics teacher education, 11(2), 107-125. https:/ / doi.org/10.1007/ s10857-0079063-7

Taylor, M. W. (2013). Replacing the 'teacher-proof'curriculum with the 'curriculum-proof'teacher: Toward more effective interactions with mathematics textbooks. Journal of Curriculum Studies, 45(3), 295-321. https:/ / doi.org/10.1080/00220272.2012.710253

Tso, T.-Y., et al. (2011) (Ed.). Junior High School Mathematics. Taipei, Taiwan: Nani Publishers (In Chinese).

Van Es, E. A., \& Sherin, M. G. (2002). Learning to notice: Scaffolding new teachers' interpretations of classroom interactions. Journal of Technology and Teacher Education, 10(4), 571-595. 
Vergnaud, G. (1998). Towards a cognitive theory of practice. In A. Sierpinska \& J. Kilpatrick (Eds.), Mathematics education as a research domain: A search for identity (pp. 227-240). Dordrecht, The Netherlands: Springer. https:/ / doi.org/10.1007/978-94-011-5190-0_14

von Glasersfeld, E. (1990) An exposition of constructivism: Why some like it radical. In R. B. Davis, C. A. Maher, \& N. Noddings (Eds.), Journal for Research in Mathematics Education. Monograph Vol. 4, Constructivist views on the teaching and learning of mathematics (pp. 19-29). Reston, VA: National Council of Teachers of Mathematics. http:/ / doi.org/10.2307/749910

Weinberg, A., \& Wiesner, E. (2011). Understanding mathematics textbooks through reader-oriented theory. Educational Studies in Mathematics, 76(1), 49-63. https:/ / doi.org/10.1007/s10649-010-9264-3

Yang, K. L. (2013). A framework for analyzing textbooks based on the notion of abstraction. For the Learning of Mathematics, 33(1), 33-39.

Yang, K. L. (2016). Analyzing mathematics textbooks through a constructive-empirical perspective on abstraction: The case of Pythagoras' theorem. Eurasia Journal of Mathematics, Science E Technology Education, 12(4), 913930. http:/ / doi.org/10.12973/eurasia.2016.1237a

Zaslavsky, O. (2005). Seizing the opportunity to create uncertainty in learning mathematics. Educational Studies in Mathematics, 60(3), 297-321. https:/ / doi.org/10.1007/s10649-005-0606-5

Zodik, I., \& Zaslavsky, O. (2008). Characteristics of teachers' choice of examples in and for the mathematics classroom. Educational Studies in Mathematics, 69(2), 165-182. https:/ / doi.org/10.1007/s10649-008-9140-6

\section{http://www.ejmste.com}

